\title{
Obituary: Dr Eric Reid
}

\section{2-16th April 2010}

It is with sadness that we announce the passing of Dr Eric Reid on $16^{\text {th }}$ April 2010. Eric was well known to many in the bioanalytical community as the founder of the Reid Bioanalytical Forum. This forum was established by Eric in 1975 at the University of Surrey in Guildford, and has run every 2 years since. Each meeting from 1975 until 1997 was followed by a hardback book summarising the proceedings, edited by Eric in his own unique style. Eric's initial concept of the meeting was to have a Forum where people actually discussed the nuts and bolts of bioanalysis, things that go wrong as well as things that worked. 'Case histories' were a regular feature. He recognized immediately that there was a lot of expertise outside academia and formed an organizing committee with industrial as well as academic colleagues. It is salutary to note that many of the topics still discussed today were topics in the 1970s: sample preparation, stability and validation, to name a few. He refers in his first book to 'laboratory lore' and the need to share experience among practitioners. Eric always wanted to be a good host and to keep the informal setting of a campus meeting. The boat trip was legendary, as was Eric's style of publicity.

Eric was born and educated in Aberdeen, where he studied chemistry. He worked at the Lister Institute in London and completed a $\mathrm{PhD}$ at University College London and then a second one at Cambridge. He did a post doctorate in the USA (Emory University, GA, USA) and then worked at the Chester Beatty Research Institute where he leaned more towards biochemistry, nucleic acid metabolism and subcellular biochemistry, particularly in cancer research. In 1963, he joined Battersea College of Technology, where he founded the biochemistry unit. In 1966 this became the biochemistry department of the University of Surrey and moved to the current Guildford location. In 1971, Eric was the founding Director of the Wolfson Bioanalytical Centre, which focused on analytical methodology and instrument development. The Bioanalytical Forum and books began in that period. Eric also established a similar series of Subcellular Methodology meetings and books.

In the late 1970s and early 1980s the Centre was subsumed into the larger Robens Institute and drastic government funding cuts were inflicted on universities. Eric, along with a number of academics, opted for early retirement from the university and set up the Guildford Academic Associates, with his wife Joan and others. They continued to run the Bioanalytical Forum until Eric decided to hand it over to the Chromatographic Society (along with a generous donation to pump prime it). From 1995 until 1999, the meetings were run by Eric under the auspices of the Chromatographic Society. In 2001, Eric took a back seat, leaving the Forum Syndicate to run things.

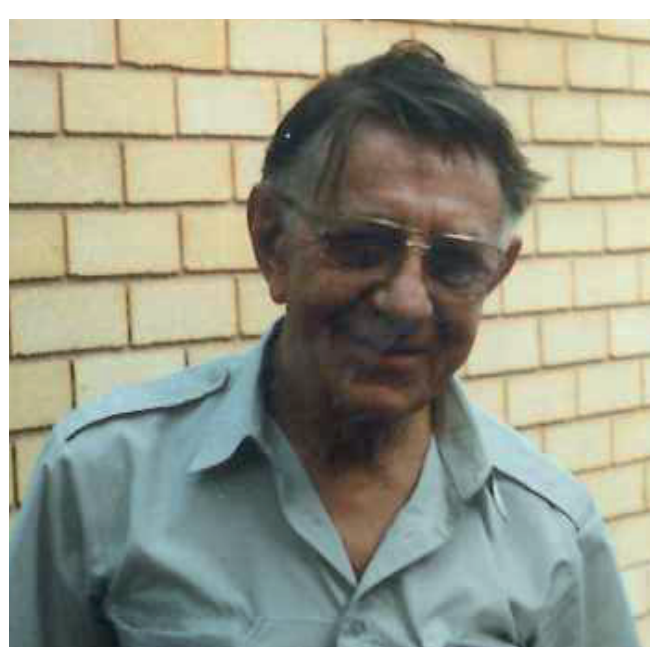

Dr Eric Reid.
Eric had little interest in material things, often seeming to skimp on small things, but disseminating substantial sums to charitable causes. These were numerous and included the education of women in developing countries and widening participation in UK universities. $\mathrm{He}$ bequeathed a 'Founders prize' to the University of Surrey biochemistry department and a bench methodology fund to the Biochemical Society.

Although in declining health, Eric was happily able to join us for a social drink at the most recent Reid Bioanalytical Forum in July 2009. He had attended every one and we will miss him. Joan predeceased Eric in March 2008; there were no children.

Written by Derek Stevenson, University of Surrey (forum co-organizer and Eric's last PhD student).
FUTURE SCIENCE 